\title{
Physical Growth and Nutritional Status among Ao Naga Children of Nagaland, Northeast India
}

\author{
Temsumongla Longkumer \\ Department of Anthropology, North-Eastern Hill University, Shillong 793022, India \\ Correspondence should be addressed to Temsumongla Longkumer; 1kr_among@yahoo.com
}

Received 24 September 2012; Accepted 26 December 2012

Academic Editor: Kaushik Bose

Copyright (C) 2013 Temsumongla Longkumer. This is an open access article distributed under the Creative Commons Attribution License, which permits unrestricted use, distribution, and reproduction in any medium, provided the original work is properly cited.

\begin{abstract}
The present study was carried out on 571 Ao Naga children including 289 boys and 282 girls aged 8 to 15 years from Mokokchung town, Nagaland. This study tried to find out the physical growth according to the height and weight and nutritional status according to the body mass index (BMI) following the classification by Cole et al. Our study revealed that the girls were taller than boys till 13 years and the boys became taller thereafter. As for weight, the girls were heavier during 10 to 14 years. The mean height and weight increased as the age advanced in both boys and girls. The prevalence of underweight was $30.12 \%$ and the prevalence of overweight was $2.28 \%$ among the Ao Naga children, and the girls were found to have a higher prevalence of overweight and the boys had a higher prevalence of underweight. This revealed that both underweight and overweight coexisted among the Ao Naga children from Mokokchung town, although the prevalence of overweight was not high.
\end{abstract}

\section{Introduction}

Physical growth of children is widely recognized as one of the most sensitive and reliable indicator of health and nutritional status in the human population [1]. Growth and maturation are maintained by the interactions of genes, hormones, and nutrients [2], and it provides an indirect measurement of the quality of life of an entire population [3]. Nutrition is the process by which living organisms receive and utilize the material necessary for the maintenance of their function as well as renewal of their function [4]. The assessment of the nutritional status of children is useful for understanding not only the health status of a community but also for the national and regional policy planning [5]. Childhood and adolescence are stages of great interest in the study of diet and assessment of nutrition, because it is a period during which the dietary habits of the future adult are consolidated $[6,7]$. One of the major health problems in many developing countries is malnutrition (undernutrition and overnutrition) which creates a lasting effect on the growth, development, and physical fitness of a person. Undernutrition is difficult to quantify, but its presence is ordinarily established in public health and clinical contexts with the use of anthropometry, specifically weight and height. Undernutrition during infancy and early childhood receives most emphasis because of its association with morbidity and mortality early in life and its long-term consequences; however, undernutrition can occur at any time during the life cycle [8]. Furthermore, the terms overweight and obesity, on the other hand, are often used interchangeably, but they are not synonymous. Overweight is characterised by a moderate degree of excess weight-for-height, whereas obesity is a more severe state [9]. Overweight and obesity are occasionally referred to as a state of overnutrition. They occur as a result of an imbalance between energy intake and energy expenditure in which intake exceeds expenditure; physical inactivity is an essential component of the equation. In general, overweight is more likely to result from behavioural factors such as dietary practices and the lack of physical activity, whereas obesity typically has a stronger behavioural and metabolic and possibly genetic etiology [10]. It has been shown that overweight or obesity assessed by the body mass index (BMI) during childhood is a strong predictor of overweight or obesity and coronary heart disease risk factors in young adulthood [11]. Overweight and obesity may occur in early childhood, but their prevalence is more common during 
childhood, adolescence, and adulthood. They have associated functional consequences and long-term health implications [9].

In developing countries, with India being one of them, the proportion of overweight and obese people now coexist with those who are undernourished [12]. According to the World Health Organization estimates, by the year 2020, noncommunicable diseases will account for approximately three quarters of all deaths in the developing world [13]. The result of studies among adolescents from Punjab, Maharashtra, Delhi, Hyderabad, and South India revealed that the prevalence of overweight and obesity was high $[14,15]$. Based on the various studies on the body mass index, appropriate practice of evidence-based health promotion in developing countries might require consideration of childhood overweight and its complications, in addition to nutritional deficiencies. Given that childhood obesity and related comorbidity, notably the metabolic syndrome, will increase the impact of a number of risk factors for adult diseases, it is reasonable to increase our knowledge about the prevalence of these disorders in developing countries, many of which are still grappling with the public health effects of malnutrition and micronutrient deficiencies [16]. In Northeast India, particularly in Nagaland, very limited studies were done on the prevalence of underweight and overweight. A recent study on the prevalence of overweight and obesity was done among the Meitei adolescent of Manipur by Dkhar and Singh [17] which showed an increase in the prevalence of overweight and obesity. Under this backdrop, this current research was therefore carried out to find out the growth status and the prevalence of underweight and overweight among the Ao Naga children in Mokokchung district of Nagaland, Northeast India.

\section{Subjects and Methods}

A cross-sectional investigation on 289 boys and 282 girls aged 8 to 15 years was carried out in Mokokchung town. Mokokchung is the home of the Ao Naga tribe and it became a full-fledged district in 1957. The Ao's speak the TibetoBurman language and follow the patrilineal system of society. Like any other Naga community, they are also engaged in various government and private services especially in urban area. Mokokchung has the highest literacy rate in the state with an average of $84.27 \%$ : male literacy is $86.14 \%$ and female literacy is $82.2 \%$. Mokokchung district has three subdivisions, namely, Tuli, Mangkolemba, and Changtongya. Mokokchung town is the district headquarters and the metropolitan agglomeration has a total population of 60, 161 [18].

For the present study, the urban area in Mokokchung district was taken into consideration, out of which seven wards, namely, Salangtem, Sangtemla, Dilong, Kichutip, Artang, Aongza, and Kumlong were selected randomly using a lottery method as mentioned in Snedecor and Cochran [19]. No statistical sampling of households and individuals was done for the purpose of the collection of data, instead an attempt was made to include all those children who were willing to cooperate for the purpose of the present study. Data on height and weight were collected using an anthropometric rod to the nearest $0.1 \mathrm{~cm}$ and weighing machine to the nearest $0.5 \mathrm{~kg}$. The parameters taken were analyzed statistically to find out the mean and standard deviation. In order to test the level of significance, both $t$-test and chi-square test were used. body mass Index (BMI) was assessed computing the international cutoff points for children and adolescents according to age and sex as recommended by Cole et al. [20]. A significance at 0.05 was used for all analyses employing MS office excel and SPSS 17 for windows software. The date of age of the children was collected from the parents taking into account the school records and birth certificate, if any. Decimal age of each subject was calculated by subtracting the date of birth of the subject from the date of data collection, using a decimal age calendar [21]. All the subjects between 7.50 and 8.50 years were classified in the age group of 8 years, whereas those falling between 8.50 and 9.50 were included in the age group of 9 years. The same principle was applied throughout to classify subjects in various age groups.

\section{Result}

Table 1 presents the mean and standard deviation of height $(\mathrm{cm})$ and weight $(\mathrm{kg})$ at each age group from 8 to 15 years in Ao Naga children. It is clear from the table that as the age advanced the mean height and weight increased for both boys and girls. From 8 to 15 years, the overall mean height in boys increased by $38.66 \mathrm{~cm}$ in boys and $27.85 \mathrm{~cm}$ in girls. As for weight, the overall increase was $25.83 \mathrm{~kg}$ in boys and $23.89 \mathrm{~kg}$ in girls.

Table 2 and Figures 1 and 2 reveal the age-wise comparison of the mean height and weight between boys and girls. It was noticed that girls were taller than boys from 8 till 13 years and at 14 and 15 years the boys became taller. However, a significant difference was noticed only at the age of 12,14 , and 15 years $(t=2.09, P<0.05 ; t=2.90, P<0.05$; and $t=8.01 P<0.05$, resp.). As for weight, the boys were heavier than girls at the age group of 8,9 , and 15 years, and a significant difference was noticed only at the age of 12 and 13 years $(t=2.08, P<0.05$, and $t=3.60, P<0.05$, resp.).

Table 3 reveals the distribution of body mass index (BMI) by age in both boys and girls. Among boys, the prevalence of overweight was found at the age group of $9(2.86 \%), 10$ $(2.78 \%), 11(2.78 \%), 12(2.63 \%)$, and 15 years $(5.71 \%)$. Also, the prevalence of underweight was found at all age groups from 8 to 15 years $(22.86 \%, 40.00 \%, 36.11 \%, 44.44 \%, 42.11 \%$, $30.56 \%, 31.58 \%$, and $25.71 \%$, resp.). As can be seen, the prevalence of underweight was higher among the younger age groups at 9, 10, 11, and 12 years. Among girls, the prevalence of overweight was found at the age group of 9 $(2.86 \%), 11(8.33 \%), 13(2.70 \%), 14(2.94 \%)$, and 15 years $(2.78 \%)$. The prevalence of underweight was found at all the age groups from 8 to 15 years $(22.22 \%, 31.43 \%, 38.24 \%$, $47.22 \%, 29.41 \%, 16.22 \%, 17.65 \%$, and $5.56 \%$, resp.). As can be seen, the prevalence of underweight was higher among younger age groups at 8 to 12 years.

Table 4 presents the distribution of underweight and overweight among boys and girls at all age groups from 8 to 15 years. It was noticed that the prevalence of underweight 
TABLE 1: Mean and standard deviation of height and weight of 8 to 15 years Ao Naga children.

\begin{tabular}{|c|c|c|c|c|c|c|c|c|c|c|}
\hline \multirow{3}{*}{ Age (years) } & \multicolumn{5}{|c|}{ Boys } & \multicolumn{5}{|c|}{ Girls } \\
\hline & \multirow[b]{2}{*}{$N$} & \multicolumn{2}{|c|}{ Height (cm) } & \multicolumn{2}{|c|}{ Weight (kg) } & \multirow[b]{2}{*}{$N$} & \multicolumn{2}{|c|}{ Height $(\mathrm{cm})$} & \multicolumn{2}{|c|}{ Weight $(\mathrm{kg})$} \\
\hline & & Mean & $\mathrm{SD}$ & Mean & $\mathrm{SD}$ & & Mean & $\mathrm{SD}$ & Mean & $\mathrm{SD}$ \\
\hline 8 & 35 & 122.49 & 4.60 & 22.94 & 2.84 & 36 & 124.08 & 5.41 & 22.86 & 2.67 \\
\hline 9 & 35 & 124.66 & 6.15 & 24.06 & 4.37 & 35 & 125.88 & 5.68 & 23.77 & 4.06 \\
\hline 10 & 36 & 128.36 & 5.45 & 25.22 & 3.60 & 34 & 130.17 & 5.62 & 25.82 & 4.32 \\
\hline 11 & 36 & 133.81 & 7.33 & 28.42 & 6.32 & 36 & 134.65 & 5.58 & 29.22 & 6.60 \\
\hline 12 & 38 & 139.41 & 7.93 & 31.79 & 6.50 & 34 & 142.90 & 6.24 & 34.82 & 5.86 \\
\hline 13 & 36 & 147.86 & 7.90 & 36.64 & 4.52 & 37 & 149.76 & 4.61 & 41.22 & 6.24 \\
\hline 14 & 38 & 154.05 & 7.55 & 42.18 & 7.33 & 34 & 149.88 & 4.40 & 43.82 & 5.81 \\
\hline 15 & 35 & 161.15 & 5.05 & 48.77 & 7.47 & 36 & 151.93 & 4.63 & 46.75 & 4.27 \\
\hline
\end{tabular}

$N=$ total number of subjects.

TABLE 2: Age-wise comparison ( $t$ value) of mean height and weight between boys and girls.

\begin{tabular}{lcc}
\hline Age (years) & Height & Weight \\
\hline 8 & 1.34 & 0.12 \\
9 & 0.86 & 0.28 \\
10 & 1.37 & 0.63 \\
11 & 0.55 & 0.53 \\
12 & $2.09^{*}$ & $2.08^{*}$ \\
13 & 1.26 & $3.60^{*}$ \\
14 & $2.90^{*}$ & 1.06 \\
15 & $8.01^{*}$ & 1.39 \\
\hline
\end{tabular}

${ }^{*}$ Significant at $5 \%$ level.

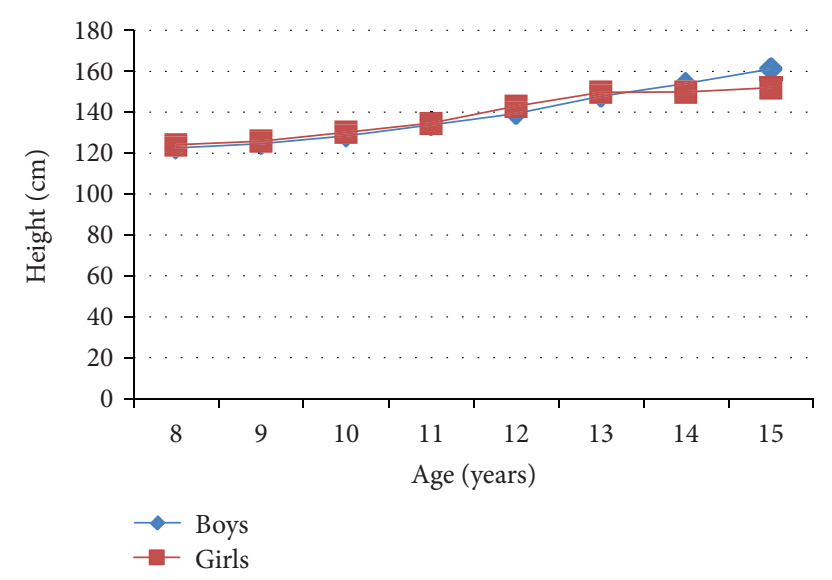

FIgURE 1: Mean height at all age groups between boys and girls.

was higher in boys (34.26\%) than in girls $(25.89 \%)$ and the prevalence of overweight was higher in girls $(2.48 \%)$ than in boys $(2.08 \%)$. However, no significant difference was revealed between boys and girls for the prevalence underweight and overweight.

\section{Discussion}

In this population of children who lived in an urban area, the girls were taller than boys at the younger age groups except at 14 and 15 years where the boys were taller. As for weight, the

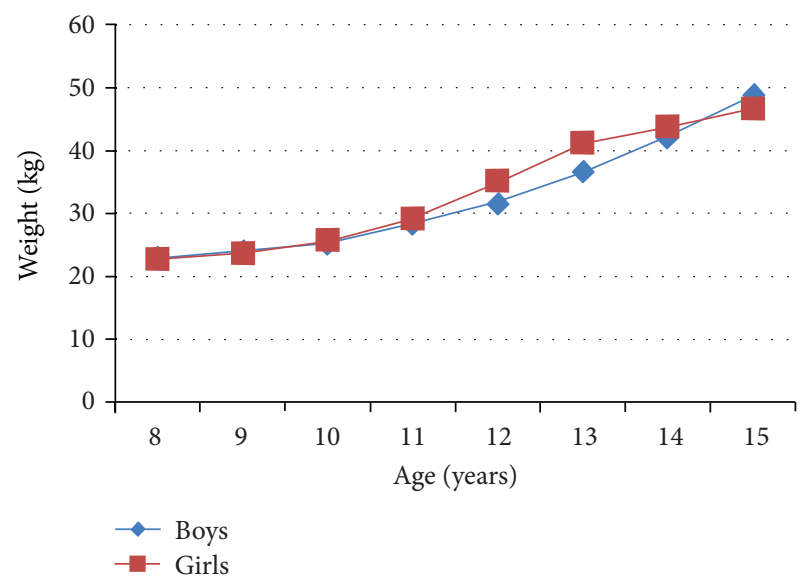

FIGURE 2: Mean weight all age groups between boys and girls.

girls were heavier than boys at 10 to 14 years. Manna et al. [22] reported that girls were taller than boys during 5 to 12 years. Ashizawa et al. [23] also found that, in the Philippine children from Manila, girls were significantly taller than boys at ages 10 and 12 years in a well-off group, and at ages 11 and 12 in a low-income group, and heavier at age 12 in both groups. In consistent with the present study, with respect to height, boys of all tribal groups were taller than girls with few exceptions during preadolescent ages, and after 14 years, boys became ultimately taller than girls [24]. Widiyani et al. [25] also found out that body weight and height for both boys and girls accelerated with the advancement of age and similar to the present study, the sex differences existed significantly after 12 years of age. The rural Ao children [26] were also found to increase in mean height and weight as the age advanced and were shorter and lighter than the urban Ao children in the present study. Peña Reyes et al. [27] revealed that the height and body mass were significantly greater in urban compared with rural children. This difference in height and weight could be attributed to the rural-urban residence, where the urban populations had better socioeconomic conditions with better nutrients to avail. Another reason could be an elevated consumption of processed foods rich in fats, sugars, and salt and low in dietary fibre with the recent development 
TABLE 3: Distribution of body mass index (BMI) by age in both boys and girls following the classification by Cole et al. (2000) [20].

\begin{tabular}{|c|c|c|c|c|c|c|}
\hline \multirow{3}{*}{ Age (years) } & \multicolumn{6}{|c|}{ Body mass index } \\
\hline & \multicolumn{3}{|c|}{ Boys } & \multicolumn{3}{|c|}{ Girls } \\
\hline & Underweight $N(\%)$ & Normal N (\%) & Overweight $N(\%)$ & Underweight $N(\%)$ & Normal N (\%) & Overweight $N(\%)$ \\
\hline 8 & $8(22.86)$ & $27(77.14)$ & $0(0.00)$ & $8(22.22)$ & $28(77.78)$ & $0(0.00)$ \\
\hline 9 & $14(40.00)$ & $20(57.14)$ & $1(2.86)$ & $11(31.43)$ & $23(65.71)$ & $1(2.86)$ \\
\hline 10 & $13(36.11)$ & $22(61.11)$ & $1(2.78)$ & $13(38.24)$ & $21(61.76)$ & $0(0.00)$ \\
\hline 11 & $16(44.44)$ & $19(52.78)$ & $1(2.78)$ & $17(47.22)$ & $16(44.44)$ & $3(8.33)$ \\
\hline 12 & $16(42.11)$ & $21(55.26)$ & $1(2.63)$ & $10(29.41)$ & $24(70.59)$ & $0(0.00)$ \\
\hline 13 & $11(30.56)$ & $25(69.44)$ & $0(0.00)$ & $6(16.22)$ & $30(81.08)$ & $1(2.70)$ \\
\hline 14 & $12(31.58)$ & $26(68.42)$ & $0(0.00)$ & $6(17.65)$ & $27(79.41)$ & $1(2.94)$ \\
\hline 15 & $9(25.71)$ & $24(68.57)$ & $2(5.71)$ & $2(5.56)$ & $33(91.67)$ & $1(2.78)$ \\
\hline
\end{tabular}

TABLE 4: Distribution of underweight and overweight among boys and girls at all age groups.

\begin{tabular}{lccc}
\hline Sex & $N$ & Underweight & Overweight \\
\hline Boys & 289 & $99(34.26 \%)$ & $6(2.08 \%)$ \\
Girls & 282 & $73(25.89 \%)$ & $7(2.48 \%)$ \\
\hline Total & 571 & $172(30.12 \%)$ & $13(2.28 \%)$ \\
\hline
\end{tabular}

$N=$ number of subjects. $\chi^{2}$ value $0.64 ; d f=1 ; P>0.05$.

in fast food restaurants in the urban area, and also regular munching of snacks including junk food especially during school recess among the children in the present study. Jim [28] also mentioned "Eaten in excess junk food makes you fat." Increased consumption of foods rich in sugars and fats is a phenomenon of concern in both developed and developing countries [29].

It is widely accepted and established from earlier papers that a large majority of children and adults of tribal groups in India suffer from undernutrition [30]. Body weight is the sum of all aspects of the body composition and is a rough measure of total energy stored. Thus, lower weights can reflect the undernutrition of the tribal communities studied [31]. However, in many developing countries, they often exhibit a paradoxical duality where under- and overweight coexist, even among the poorest [32]. The prevalence of overweight and obesity may be due to the reduction in energy expenditure because of an inactive life style accompanied by an increase in the energy intake [33]. In the present study, the prevalence of normal body weight was higher, followed by underweight and then overweight at all age groups in both boys and girls. A high prevalence of underweight among the children in the present study could be due to the imbalance between diet needed for proper growth and regular energy expenditure through physical activity level, as Bouchard [34] had also mentioned that low-fat diets and regular physical activity contributed to weight loss and weight maintenance. The high prevalence of underweight was also observed in the tribal groups of Rajasthan in both adolescent boys and girls on the basis of body mass index [31]. Widiyani et al. [25] in their study among the Javanese children age 4 to 20 years stated that the prevalence of underweight was low because the subjects under study came from a well-off family. The high prevalence of underweight among children in the present study could also be due to the fact that most of these underweight children belonged to the lower income group without proper nutrients required for a proper body growth. The prevalence of overweight, on the other hand, could be attributed to the lack of physical activity along with the increase in fat containing diet especially junk food containing saturated fat and copious amount of sugar and salt. Laxmaiah et al. [15] also found that approximately 22 percent of adolescents in their study preferred to consume junk foods because it was their favourite dish and that the prevalence of overweight was higher among those who were fond of junk foods. Another reason might be these overweight children came from better socioeconomic conditions so that they can avail better nutrients. The girls in the present finding were found to have a higher prevalence of overweight that ranged from 2.70 to 8.57 percent than the boys that ranged from 2.44 to 5.71 percent. Various studies also were in consonance with the present finding $[17,25]$. Among girls, more than boys, earlier onset of puberty and early menarche were associated with higher levels of fatness and higher risk for overweight and obesity. In contrast, boys ordinarily declined in relative fatness during puberty because of the rapid growth of the fat-free mass [9]. Also, early-maturing boys and girls tended to have, on average, elevated body mass index as compared with late maturing boys and girls, which persisted through adolescence [9].

The present study showed that the prevalence of underweight was $30.12 \%$ and overweight was $2.28 \%$ among the Ao children during the age groups of 8 to 15 years. This revealed that both underweight and overweight coexisted among them, although the prevalence of overweight was not high. Therefore, nutritional status including both under- and overnutrition of the Ao Naga children from the urban area requires attention for the improvement of the health status of both children and adults, as these health problems early in life may have long-term consequences that may persist 
into adulthood. Special preventive measures concerning the prevalence of overweight and its consequences should be made well known, as with the advancement of science and technology, and with the ever changing lifestyle accompanied by diminishing habitual exercise and a more sedentary style of leisure time activity, the prevalence of overweight and obesity is increasing tremendously causing a thread to many people all over the world, particularly the developing countries, India being one of them.

\section{Acknowledgments}

The author would like to thank all participating subjects of the present study for their cooperation and her research guide Dr. J. W. Dkhar for his guidance. The author is thankful for the financial support received from the Rajiv Gandhi National Research Fellowship (RGNRF), University Grants Commission.

\section{References}

[1] P. H. Eveleth and J. M. Tanner, Worldwide Variation in Human Growth, Cambridge University Press, Cambridge, Mass, USA, 2nd edition, 1990.

[2] R. M. Malina, C. Bouchard, and O. Bar-Or, "Physical activity as a factor in growth, maturation, and performance," in Growth, Maturation, and Physical Activity, M. Malina, C. Bouchard, and O. Bar-Or, Eds., pp. 509-525, Human kinetics, 2nd edition edition, 2004.

[3] M. de Onis and M. Blössner, "The World Health Organization global database on child growth and malnutrition: methodology and applications," International Journal of Epidemiology, vol. 32, no. 4, pp. 518-526, 2003.

[4] S. Vaid and N. Vaid, "Nutritional status of ICDS and non-ICDS children," Journal of Human Ecology, vol. 18, no. 3, pp. 207-212, 2005.

[5] R. Khongsdier, "A growth and nutritional status of the War Khasis children," Journal of Human Ecology, vol. 6, pp. 261-268, 1995.

[6] N. Lien, L. A. Lytle, and K. I. Klepp, "Stability in consumption of fruit, vegetables, and sugary foods in a cohort from age 14 to age 21," Preventive Medicine, vol. 33, no. 3, pp. 217-226, 2001.

[7] D. Neumark-Sztainer, M. Wall, C. Perry, and M. Story, "Correlates of fruit and vegetable intake among adolescents: findings from project EAT," Preventive Medicine, vol. 37, no. 3, pp. 198-208, 2003.

[8] R. M. Malina, C. Bouchard, and O. Bar-Or, "Undernutrition in childhood and adolescence," in Growth, Maturation, and Physical Activity, M. Malina, C. Bouchard, and O. Bar-Or, Eds., pp. 509-525, Human Kinetics Books, Champaign, Ill, USA, 2d edition, 2004.

[9] R. M. Malina, C. Bouchard, and O. Bar-Or, "Obesity in childhood and adolescence," in Growth, Maturation, and Physical Activity, M. Malina, C. Bouchard, and O. Bar-Or, Eds., pp. 527-551, Human Kinetics Books, Champaign, Ill, USA, 2d edition, 2004.

[10] C. Bouchard, "The obesity epidemic: introduction," in Physical Activity and Obesity, C. Bouchard, Ed., pp. 3-20, Human Kinetics Books, Champaign, Ill, USA, 2000.

[11] I. Janssen, P. T. Katzmarzyk, S. R. Srinivasan et al., "Combined influence of body mass index and waist circumference on coronary artery disease risk factors among children and adolescents," Pediatrics, vol. 115, no. 6, pp. 1623-1630, 2005.

[12] B. M. Popkin, "The shift in stages of the nutritional transition in the developing world differs from past experiences," Public Health Nutrition, vol. 5, no. 1, pp. 205-214, 2002.

[13] World Health Organization, Global Strategy For NonCommunicable Disease Prevention and Control (Draft), World Health Organization, Geneva, Switzerland, 1997.

[14] S. Kaur, U. Kapil, and P. Singh, "Pattern of chronic diseases amongst adolescent obese children in developing countries," Current Science, vol. 88, no. 7, pp. 1052-1056, 2005.

[15] A. Laxmaiah, B. Nagalla, K. Vijayaraghavan, and M. Nair, "Factors affecting prevalence of overweight among 12- to 17year-old urban adolescents in Hyderabad, India," Obesity, vol. 15, no. 6, pp. 1384-1390, 2007.

[16] R. Kelishadi, "Childhood overweight, obesity, and the metabolic syndrome in developing countries," Epidemiologic Reviews, vol. 29, no. 1, pp. 62-76, 2007.

[17] J. W. Dkhar and M. S. Singh, "Prevalence of overweight and obesity among the Meitei adolescent of Manipur, India," Anthropologist, vol. 14, no. 4, pp. 347-351, 2012.

[18] Census of India, Provisional Population Totals, series-13, Nagaland, India, 2001.

[19] G. W. Snedecor and W. G. Cochran, Statistical Methods, The Iowa State University Press, Ames, Iowa, USA, 1967.

[20] T. J. Cole, M. C. Bellizzi, K. M. Flegal, and W. H. Dietz, "Establishing a standard definition for child overweight and obesity worldwide: international survey," British Medical Journal, vol. 320, no. 7244, pp. 1240-1243, 2000.

[21] J. M. Tanner, J. Hiernaux, and S. Jarman, "Growth and physique studies," in Human Biology: A Guide to Field Methods, J. S. Weiner and J. A. Lourie, Eds., pp. 315-340, Blackwell Publications, Oxford, UK, 1969.

[22] P. K. Manna, D. De, T. K. Bera, K. Chatterjee, and D. Gosh, "Anthropometric assessment of physical growth and nutritional status among school children of North Bengal," Anthropologist, vol. 13, no. 4, pp. 299-305, 2011.

[23] K. Ashizawa, C. Kumakura, and A. Kusumoto, "Growth of Philippine children in reference to socioeconomic environment," Anthropological Science, vol. 106, no. 2, pp. 77-94, 1998.

[24] M. K. Bhasin and S. Jain, "Biology of the Tribal groups of Rajasthan, India: age changes in somatotype," Anthropologist, vol. 9, no. 4, pp. 257-265, 2007.

[25] T. Widiyani, B. Suryobroto, S. Budiarti, and A. Hartana, "The growth of body size and somatotype of Javanese children age 4 to 20 years," HAYATI Journal of Biosciences, vol. 18, no. 4, pp. 182-192, 2011.

[26] T. A. Jamir, Nutritional status and physical growth of Ao children of Mokokchung district, Nagaland [Ph.D. thesis], North-Eastern Hill University, Shillong, India, 2001.

[27] M. E. Peña Reyes, S. K. Tan, and R. M. Malina, "Urban-rural contrasts in the growth status of school children in Oaxaca, Mexico," Annals of Human Biology, vol. 30, no. 6, pp. 693-713, 2003.

[28] B. Jim, "The disadvantages of junk food," 2011, http://www .livestrong.com/article/425388-the-disadvantages-of-junkfood/.

[29] A. Langlois, "Obesity the big issue," 2003, Report prepared for J.P. Morgan.

[30] M. K. Bhasin and S. Jain, "Biology of the tribal groups of Rajasthan, India: 7. Occurrence of nutritional deficiencies," Anthropologist, vol. 9, no. 4, pp. 281-288, 2007. 
[31] M. K. Bhasin and S. Jain, "Biology of the tribal groups of Rajasthan, India: 6. A comparative study of the nutritional status," Anthropologist, vol. 9, no. 4, pp. 273-279, 2007.

[32] B. Caballero, "A nutrition paradox: underweight and obesity in developing countries," The New England Journal of Medicine, vol. 352, no. 15, pp. 1514-1516, 2005.

[33] E. B. Bodzsar, A. Zsakai, K. Jakab, and K. B. Toth, "Body fatness and sexual maturation status," Anthropological Notebooks, vol. 10, no. 1, pp. 12-17, 2005.

[34] C. Bouchard, "Introduction," in Physical Activity and Obesity, C. Bouchard, Ed., pp. 3-19, Human Kinetics, Champaign, Ill, USA, 2000. 

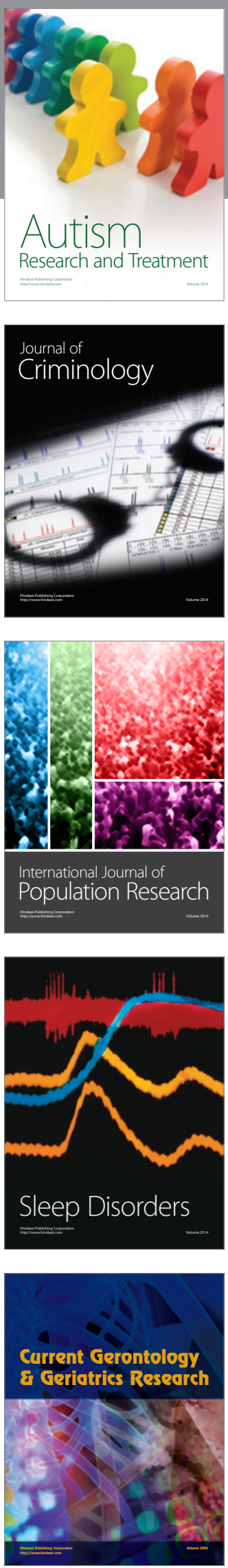
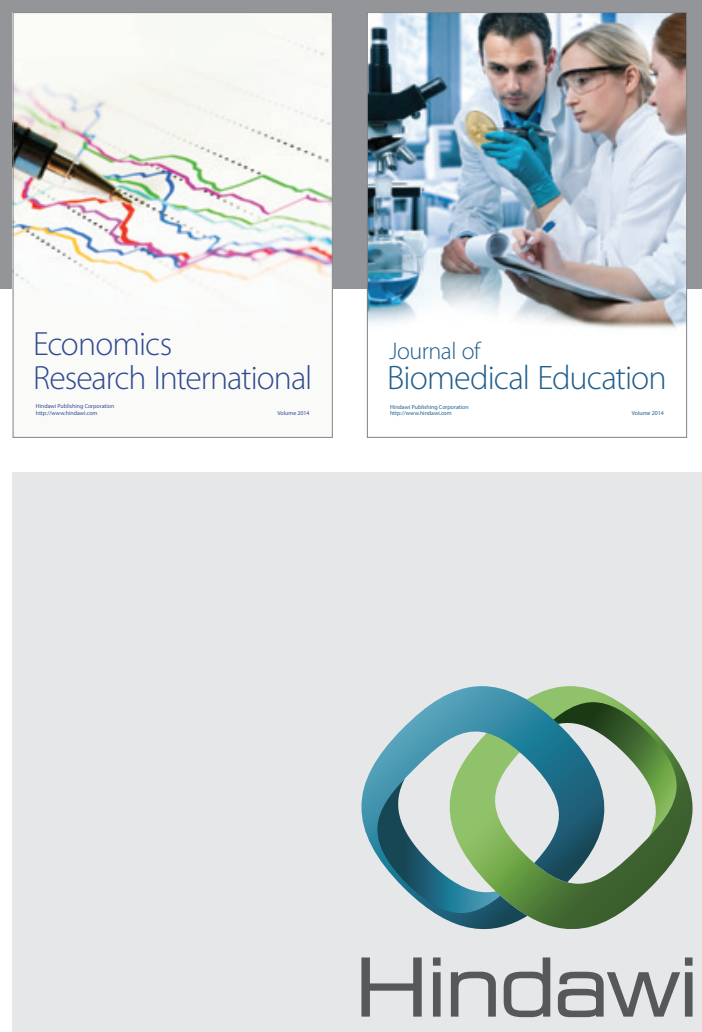

Submit your manuscripts at

http://www.hindawi.com
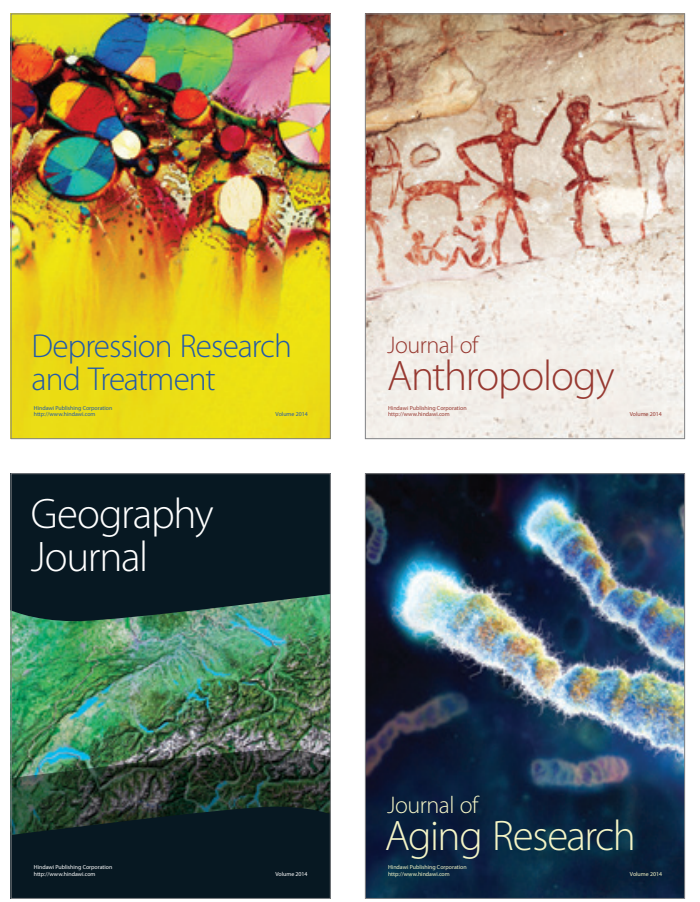
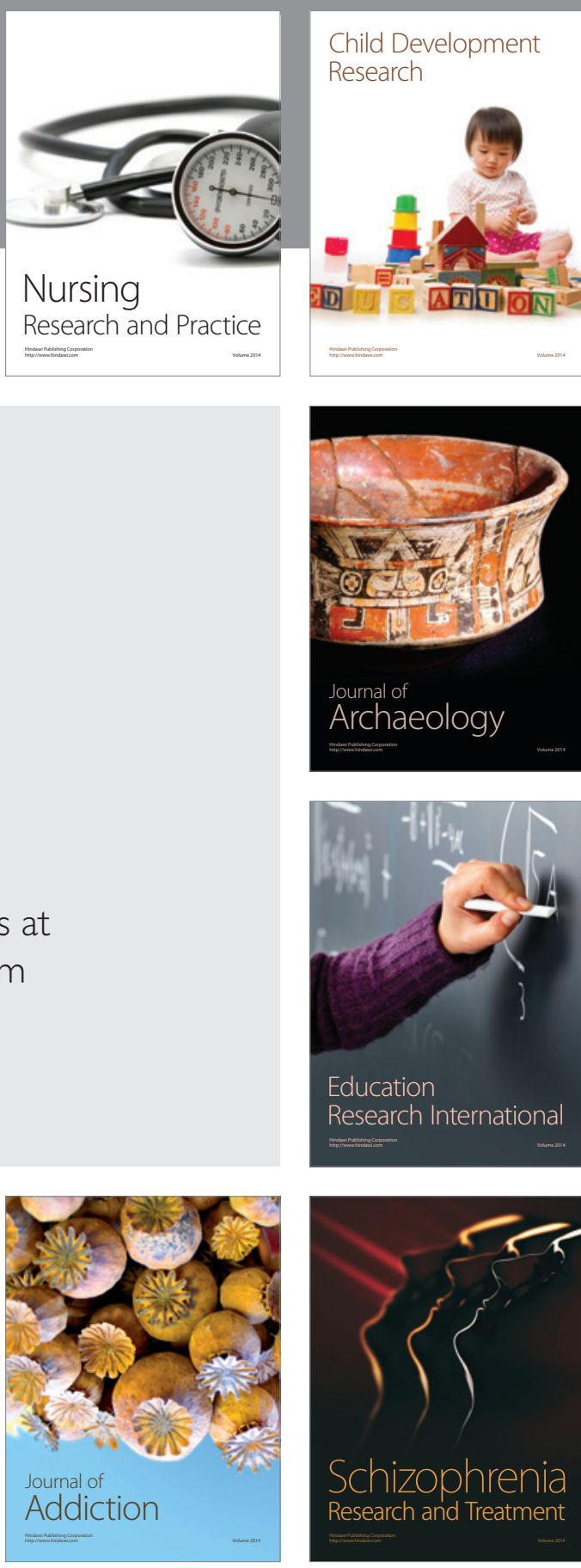

(D)
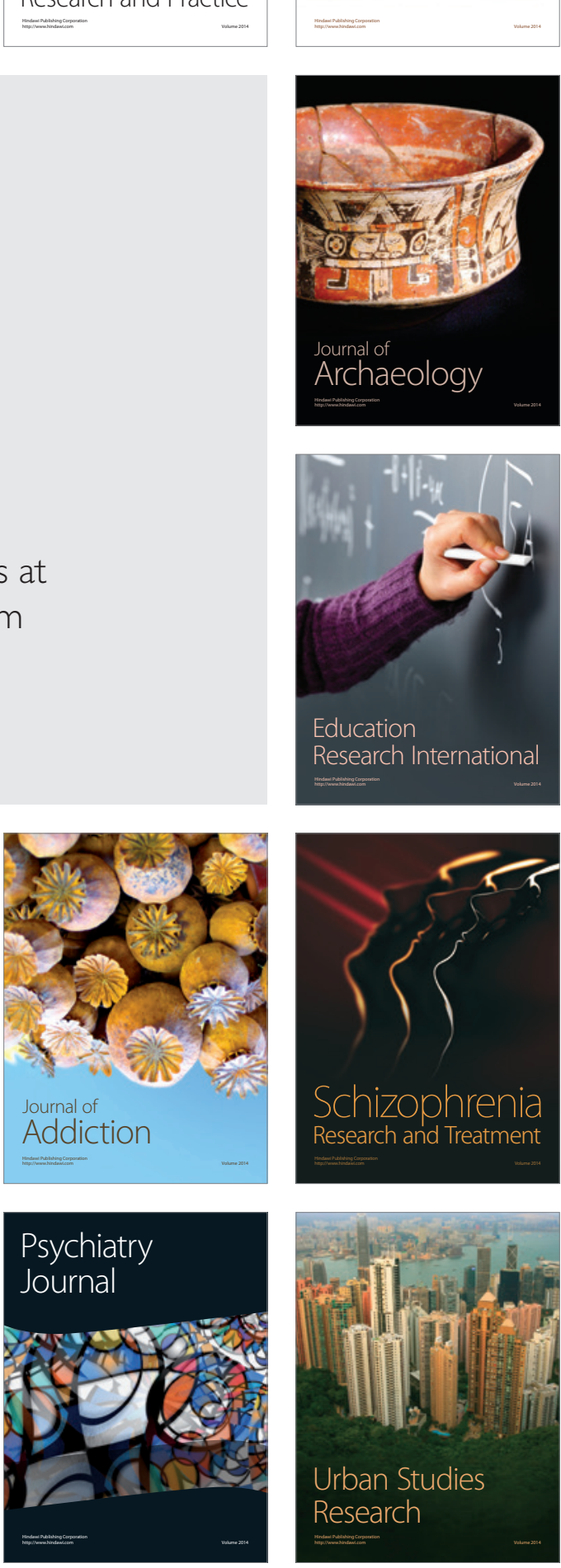